\title{
TROTE SOLIDÁRIO E SUSTENTÁVEL: “O \\ PAPEL DO CALOURO DA UFPA" COMO \\ MECANISMO DE EDUCAÇÃO AMBIENTAL NA \\ CIDADE UNIVERSITÁRIA PROF. JOSÉ DA \\ SILVEIRA NETTO-UFPA
}

Cássila dos Santos Simão - engcassilasimao@yahoo.com.br

Universidade Federal do Pará

Fábio Sergio Lima Brito - fabio.lima.ufpa@gmail.com

Universidade Federal do Pará

Samara Avelino de Souza França - samara_avelino@ hotmail.com

Universidade Federal do Pará

Lúcia de Fátima Almeida - ifa@ufpa.com

Universidade Federal do Pará

Liana Figueira Machado - liana@ufpa.com 


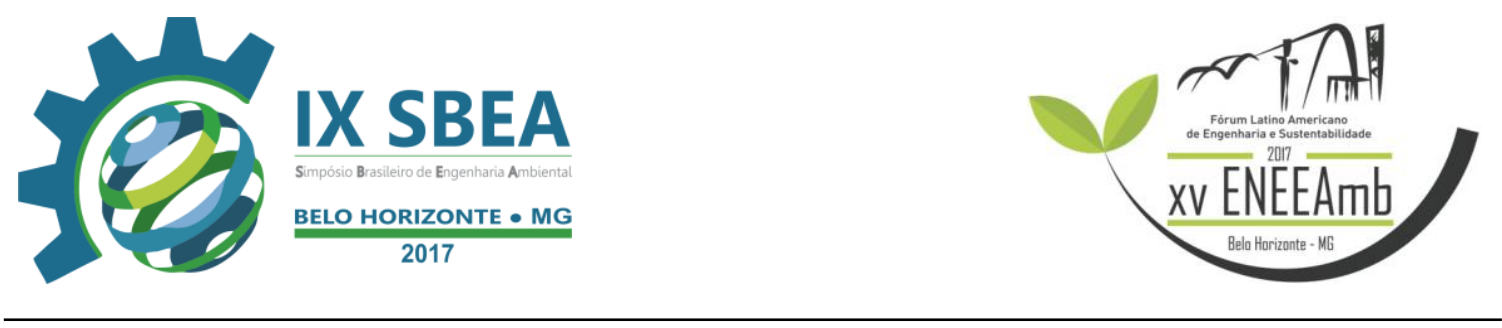

\section{RESUMO}

A necessidade de práticas de Educação Ambiental (EA) integradoras decorre da percepção de que diálogos e reflexões não são suficientes para compreender a complexidade ambiental da relação indivíduo-natureza. Logo, estas atividades são essenciais para unir os atores sociais que se mobilizam para proteger o meio, num processo educativo compromissado com a sustentabilidade e a participação social. Nesse contexto, a Coordenadoria de Meio Ambiente (CMA), da Prefeitura da Universidade Federal do Pará (UFPA), realiza desde 2012, o trote solidário e sustentável "O Papel do Calouro da UFPA". Durante uma semana, os calouros são convidados a doar todo o papel que serviu de apoio na sua aprovação (apostilas, cadernos). $\mathrm{O}$ material arrecadado é destinado às cooperativas de catadores de materiais recicláveis da Região Metropolitana de Belém, Pará. Ademais, esta prática oportuniza que alunos de Engenharia Sanitária e Ambiental participem como voluntários. Com o objetivo de relatar a experiência das três últimas edições do trote, fez-se um levantamento bibliográfico sobre EA e resíduos sólidos, pesquisa documental no acervo da CMA e a análise de questionários aplicados aos calouros, para traçar um perfil dos mesmos. Verificou-se que muitos têm uma preocupação ambiental e social no meio em que vivem e interesse em participar de práticas socioambientais como o trote. Além disso, a quantidade de papel arrecadado aumentou: 1.072kg em 2013, 1.493kg em 2014 e $1.555 \mathrm{~kg}$ em 2015. Portanto, a iniciativa tem cumprido seu papel como atividade de responsabilidade socioambiental que incentiva a comunidade universitária e a sociedade em geral a participar de novas ações.

Palavras-chave: Educação Ambiental, Coordenadoria de Meio Ambiente, Ações Socioambientais.

\section{INTRODUÇÃO}

A dimensão ambiental apresenta-se como uma questão que envolve um conjunto de atores e o meio. Para Jacobi (2004), dentro do universo educativo, observa-se a necessidade de potencializar o engajamento entre os profissionais e a comunidade, inclusive universitária, dentro de uma perspectiva interdisciplinar, de troca de saberes e práticas cotidianas, tradicionais e científicas. 


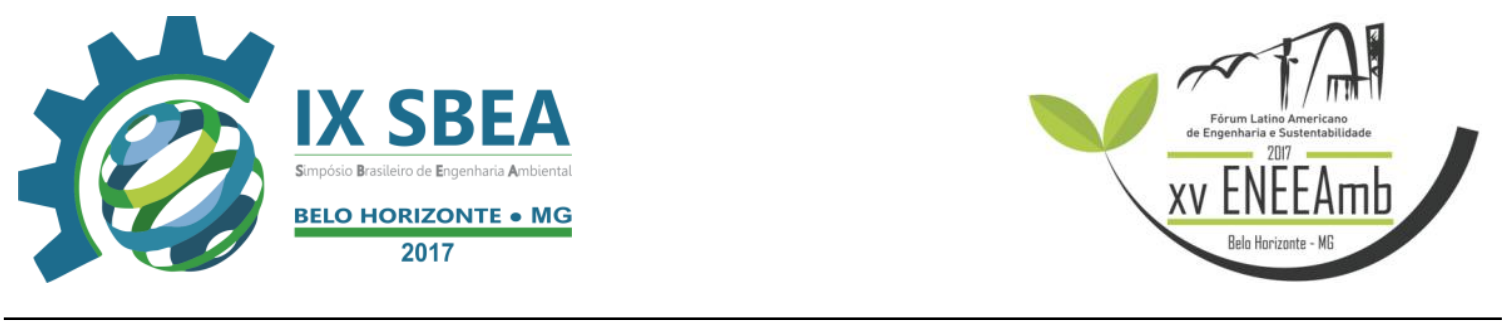

Nesse aspecto a educação ambiental atua como mediadora de reflexões e atividades que fortaleçam a ação coletiva, a fim de proteger o meio e os recursos ambientais. Trata-se, pois, de "uma dimensão do discurso e da prática da educação, orientada à prevenção e a resolução dos problemas concretos colocados pelo meio ambiente, graças a um enfoque interdisciplinar e à participação ativa e responsável de cada indivíduo e da coletividade" (DÍAZ, 2002, pág. 53).

Desta forma, a partir da construção de uma relação critica entre ser humano e natureza, propõem-se um modelo de educação política, pautada na formação de atores sociais e práticas transformadoras. Segundo Vargas (2005), a Educação Ambiental (EA) contribui para a construção uma sociedade mais sustentável, democrática e participativa, capaz de estabelecer uma rede solidária de relações, preocupando-se com as futuras gerações.

Nesse contexto, a Lei No 9.795 de 27 de abril de 1999, além de definir educação ambiental, aponta-a como componente essencial e permanente em todos os níveis e modalidades de ensino, cujo caráter humanista, participativo e democrático engloba a interrelação de aspectos econômicos, políticos, culturais, e sociais a fỉm de construir uma sociedade ambientalmente equilibrada.

Sabendo da necessidade de práticas educacionais integradoras, a Coordenadoria de Meio Ambiente (CMA) da Prefeitura da Universidade Federal do Pará (UFPA), realiza desde 2012 o Trote Solidário e Sustentável "O Papel do Calouro da UFPA”. O Trote ocorre na Semana do Calouro, evento realizado por Instituições de Ensino Superior para dar as boas vindas aos alunos aprovados no processo seletivo.

O título do trote remete ao papel social e ambiental dos calouros no meio; e também ao material arrecadado: o papel. Assim, durante a semana do calouro há o recebimento de papel (apostilas, cadernos e rascunhos) utilizado pelos calouros para o ingresso no ensino superior, o qual é destinado às cooperativas de catadores de materiais recicláveis da Região Metropolitana de Belém, por meio do Programa da Coleta Seletiva Solidária (CSS).

Através de divulgação, inclusive por meio de e-mail e redes sociais, a CMA convida os calouros a participarem da inciativa e convoca alunos do curso de Engenharia Sanitária e Ambiental para que estes se inscrevam como voluntários durante 
a realização da atividade. Nesse sentido, o objetivo desse trabalho é relatar a experiência dos três anos de atividade do trote solidário e sustentável no processo de incentivo a EA na Cidade Universitária Prof. José da Silveira Netto (UFPA).

\section{MATERIAL E MÉTODOS}

O trote solidário e sustentável intitulado "O Papel do Calouro da UFPA" é realizado desde o ano de 2012 na Cidade Universitária Prof. José da Silveira Netto (UFPA), sempre durante a semana do calouro, que é geralmente executado no mês de março, podendo ter variação devido o calendário acadêmico. Esta ação socioambiental consiste em arrecadar basicamente material reciclável como papel (acúmulo de apostilas, livros desatualizados, arquivos escolares antigos, revistas, etc.), para a destinação às cooperativas de materiais recicláveis que são vinculadas à Instituição, por meio de edital.

A ação tem divulgação realizada em parceria com a Assessoria de Comunicação da UFPA (ASCOM), Cerimonial da UFPA, nas chamadas durante a programação de abertura da Semana do Calouro, das Coordenações Acadêmicas dos Cursos, do Diretório Central dos Estudantes (DCE) e Centros Acadêmicos (CA) na divulgação durante a programação de orientação acadêmica.

3.1 Áreas de estudo: A Cidade Universitária Prof. José da Silveira Netto-UFPA está localizada na cidade de Belém do Pará, às margens do Rio Guamá e ocupa uma área de 450 hectares, sendo dividida em quatro setores: Setor Básico (Campus I), Setor Profissional (Campus II), Setor Esportivo (Campus III) e Setor Saúde (Campus IV). 

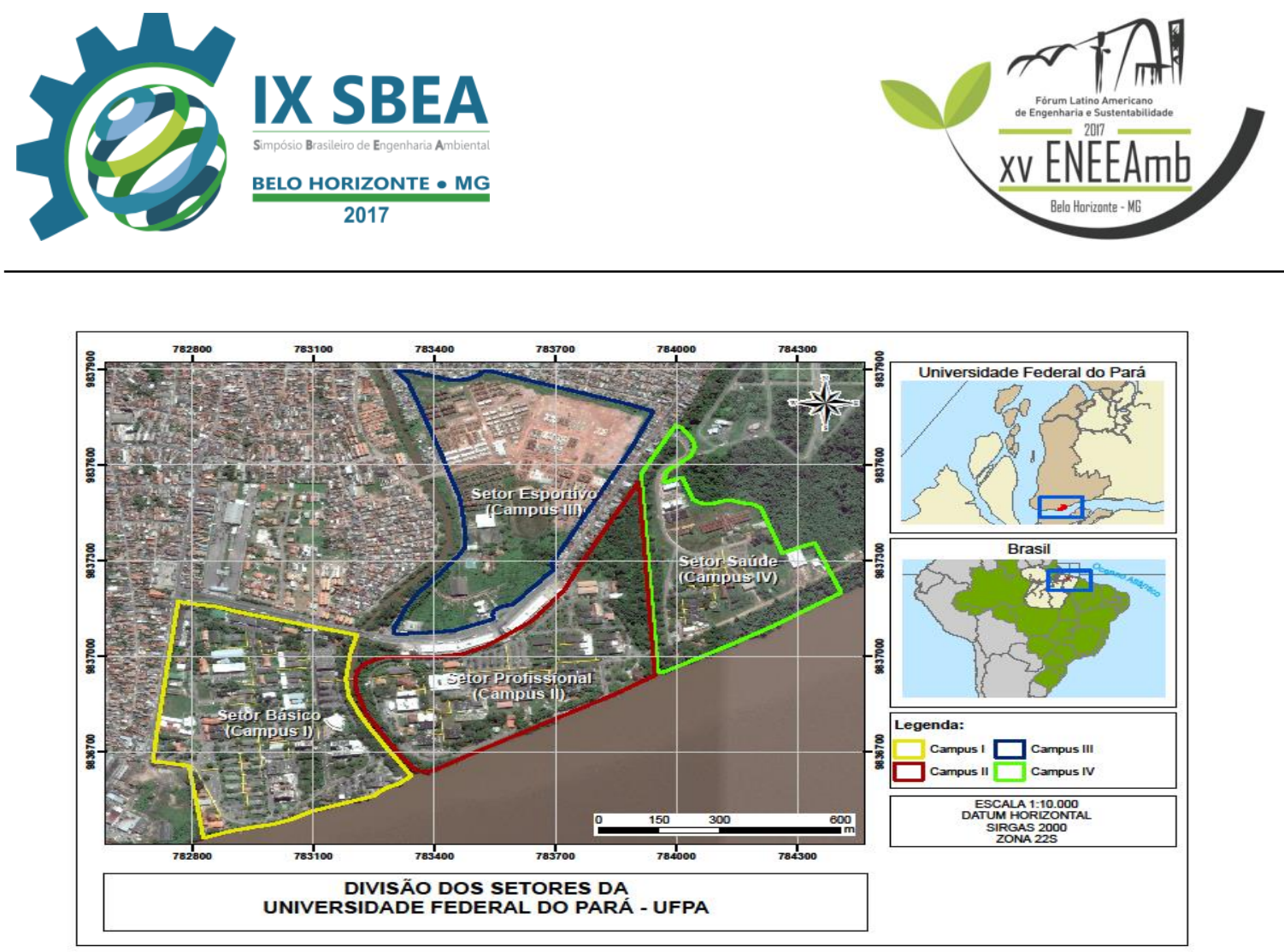

Figura 01. Mapa de localização da Cidade Universitária Prof. José da Silveira Netto-UFPA Fonte: SIMÃO \& MELLO, 2015

3.2 Materiais e Equipamentos: Para realização da ação do trote são necessários alguns equipamentos e materiais como: máquina fotográfica e uma balança para a pesagem dos resíduos recicláveis, sendo este manual de modelo "Balmak 101", com carga máxima de $150 \mathrm{~kg}$ (cento e cinquenta quilogramas), além de canetas, folhas de papel e pranchetas para anotação.

3.3 Pesquisa Bibliográfica: Para a elaboração deste trabalho foi necessário o levantamento bibliográfico por meio de consultas a artigos, dissertações, livros, monografias, trabalho de conclusão de curso (TCC) e trabalhos científicos que conduziram a uma reflexão teórica sobre conceitos e ideias importantes de autores que tratam da temática dos resíduos sólidos, educação ambiental e políticas públicas socioambientais.

3.4 Pesquisa Documental: Esta pesquisa consistiu na busca por documentos com informações sobre a realização da atividade, tais como: e-mail, memorandos, ofícios, registros fotográficos e questionários aplicados durante os anos 2013, 2014 e 2015. Estes dados encontram-se nos arquivos da CMA.

3.5 Levantamento de dados: Os levantamentos foram obtidos por meio de indicadores quantitativos e qualitativos, por meio de um questionário estruturado, aplicado durante a realização do trote, com perguntas abertas e fechadas. Esta entrevista possibilitou o conhecimento sobre o perfil socioambiental dos calouros. Vale ressaltar 


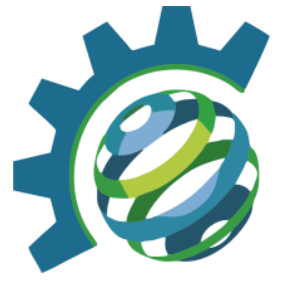

que, ao longo desses anos de realização da atividade foram aplicados 236 questionários aos calouros e 75 aos voluntários, somando um total de 311 questionários.

\section{RESULTADOS E DISCUSSÕES}

Durante os três anos da realização do Trote Solidário e Sustentável foram realizadas diversas atividades, entre elas, destacam-se:

Orientação acadêmica: é o momento em que os voluntários da ação fazem visitas às unidades acadêmicas para informar os objetivos do trote, dias, horários para entrega dos papéis, rascunhos e apostilas etc., (Figura 2-a)

Arrecadação: é o momento na qual os calouros entregam os materiais aos voluntários do trote que, em geral, acontece uma interação entre veteranos e calouros (Figuras 2-b).

Aplicação de questionário: todos os calouros que entregam seus papeis ao projeto são convidados a colaborar em uma pesquisa preenchendo um questionário que pretende reconhecer o perfil socioambiental de cada estudante (Figuras 2-d).

Pesagem: é parte posterior da arrecadação e consiste em pesar todo o material que chega (Figuras 2-c).

Triagem: consiste na separação dos materiais recicláveis na qual são acondicionados em sacos plásticos de 100 litros com divisões de caderno, livros, apostilas, jornais e outros (Figuras 2-e).

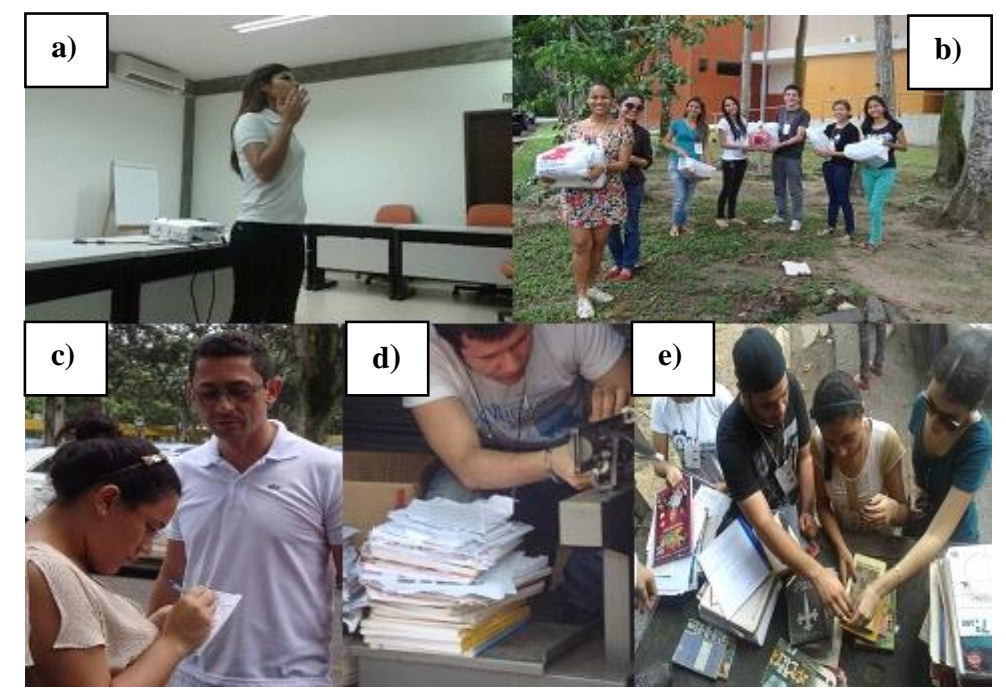

Figura 02. Atividades desenvolvidas durante o trote solidário e sustentável Fonte: Prefeitura da UFPA, 2013,2014,2015 


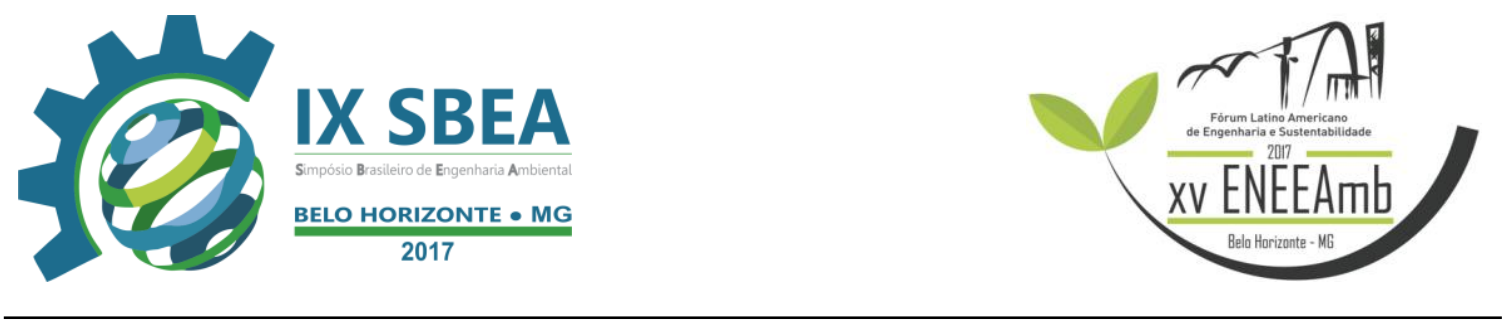

\section{Questionários}

Com o objetivo de traçar o perfil socioambiental dos calouros que adentram a UFPA é aplicado um questionário contendo seis perguntas. A pesquisa tem o objetivo de avaliar e identificar aqueles que têm interesse em aderir aos trabalhos voluntários da CMA bem como ser parceiro de outras atividades desenvolvidas pela equipe de educação ambiental da CMA.

Conforme o Gráfico 01, grande parte dos calouros adentram a UFPA com o foco de participar de uma formação justa e comprometida com a sociedade, dentro destas questões pode-se incluir o meio ambiente, pois dentro de uma sociedade desenvolvida a preocupação ambiental com o uso sustentável dos recursos naturais faz se necessária.

- Participar de um curso gratuito de nível superior

- Garantir uma profissão que possibilite ingressar no marcado de trabalho

- Participar de uma formação profissional comprometida com o desenvolvimento de uma sociedade mais justa

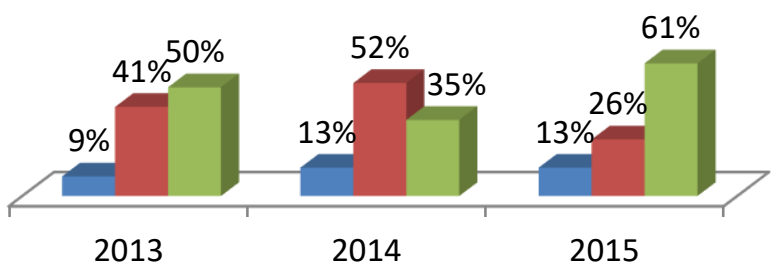

Gráfico 1. Expectativa quanto ao ingresso na UFPA

Fonte: Prefeitura da UFPA 2013,2014,2015

De acordo com o Gráfico 02, a grande maioria dos novos universitários está em fase de desenvolvimento da consciência ambiental e ações como o trote vem para fortalecer ainda mais as práticas socioambientais que são amplamente discutidas, mas pouco operacionalizadas. 


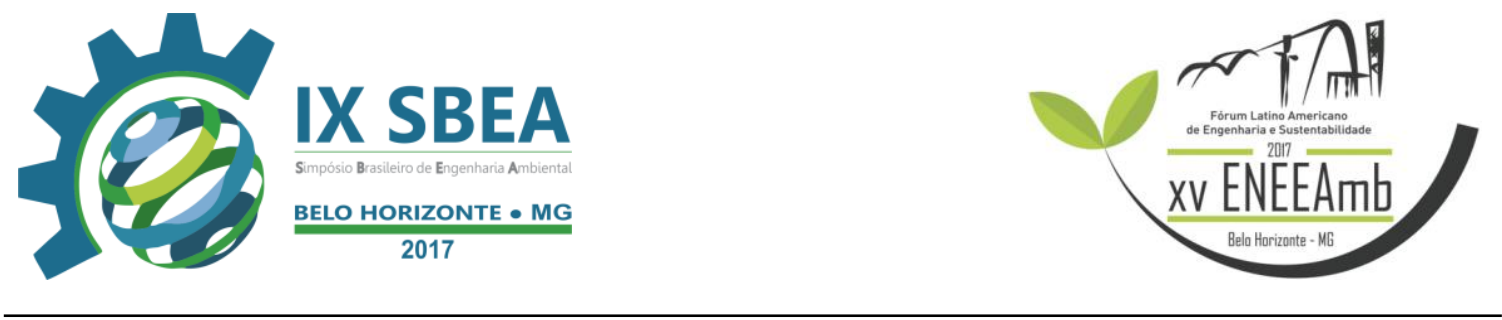

nunca se preocupou com o assunto

- Vem buscando conhecer o assunto, encontrando-se numa fase inicial

- Apresenta interesse no assunto e já participa de alguma ação ligada ás questões ambientais

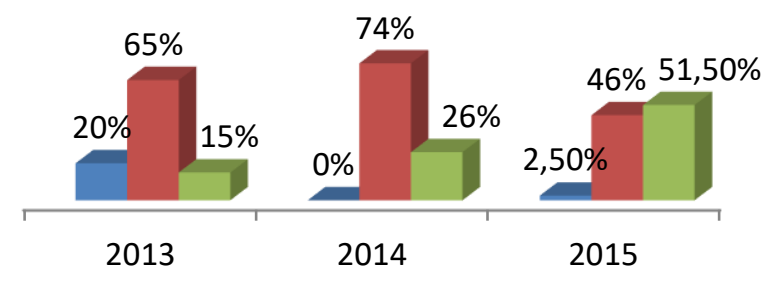

Gráfico 2. Nível de conscientização ambiental

Fonte: Prefeitura da UFPA 2013,2014,2015

Quanto ao conhecimento do termo coleta seletiva grande parte dos entrevistados responderam obter conhecimento sobre o assunto. A avaliação desses resultados é satisfatória, visto que, a aceitação por projetos ambientais irá ser mais rápida e abrangente nesses casos (Gráfico 3).

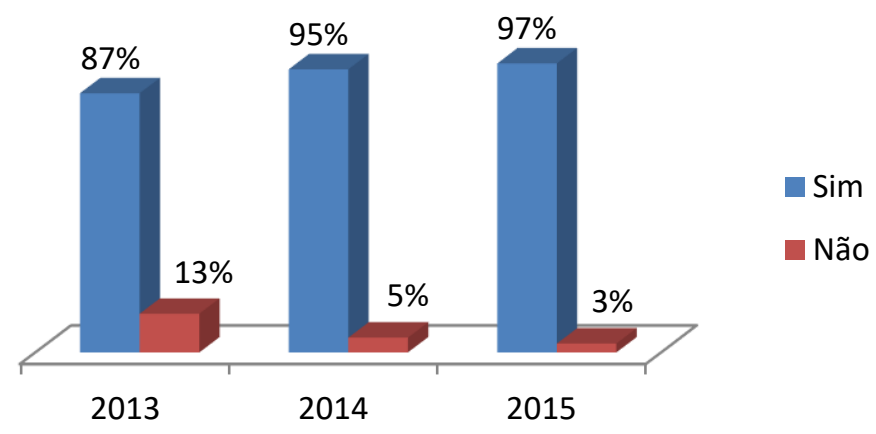

Gráfico 3. Conhecimento do termo coleta seletiva

Fonte: Prefeitura da UFPA 2013,2014,2015

Quando questionados sobre o motivo que levou os calouros a participarem da ação de sensibilização, a grande maioria respondeu para evitar que o material fosse desperdiçado, embora esse não seja o principal objetivo da ação, já que o trote visa contribuir com o aumento da geração de renda dos catadores e a destinação final sanitariamente e ambientalmente correta dos resíduos. O foco não deixou de ser 


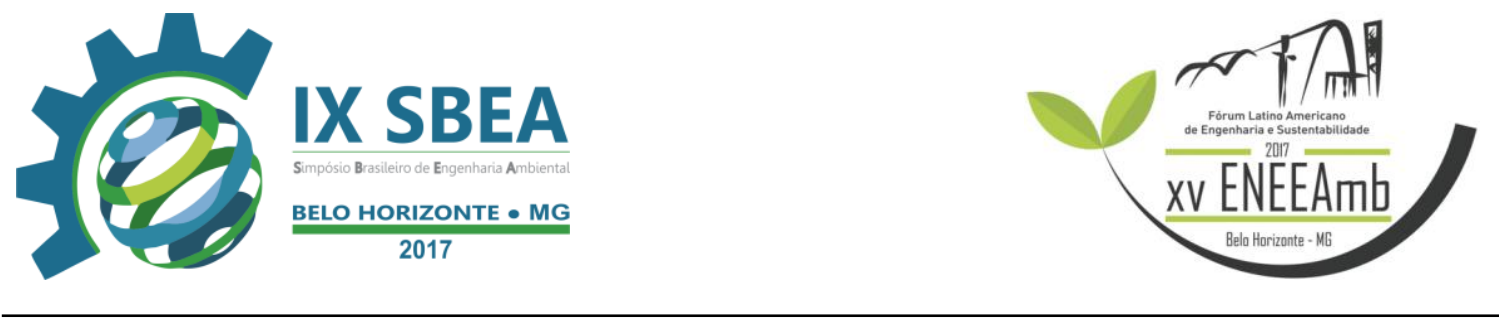

alcançado, pois os resquícios voltam ao ciclo produtivo por meio da reciclagem (Gráfico 4).

- Desocupar espaço em sua casa

- Colaborar para aumentar a renda dos catadores de materiais recicláveis, melhorando sua qualidade de vida

Evitar que todo esse material seja desperdiçado

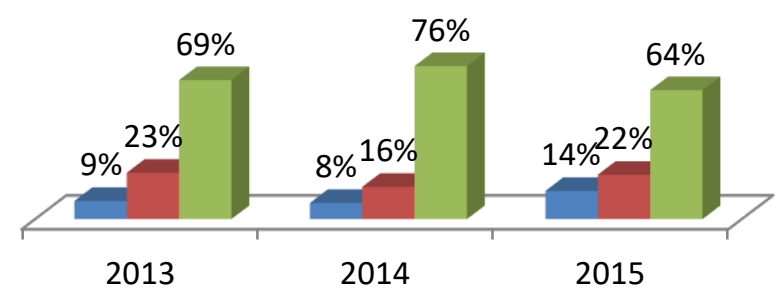

Gráfico 4. Motivo de participação dos calouros

Fonte: Prefeitura da UFPA 2013,2014,2015

Por último, observou-se que, mais de noventa por cento dos alunos tem interesse em participar de ações que envolvem temáticas e práticas educacionais como o trote solidário e sustentável na qual sensibiliza a comunidade universitária no que diz respeito ao descarte adequado dos resíduos sólidos. Vale ressaltar que, este resultado foi de suma importância para CMA, porque baseado nessas respostas outras atividades foram realizadas ao longo desses três anos (Gráfico 5).

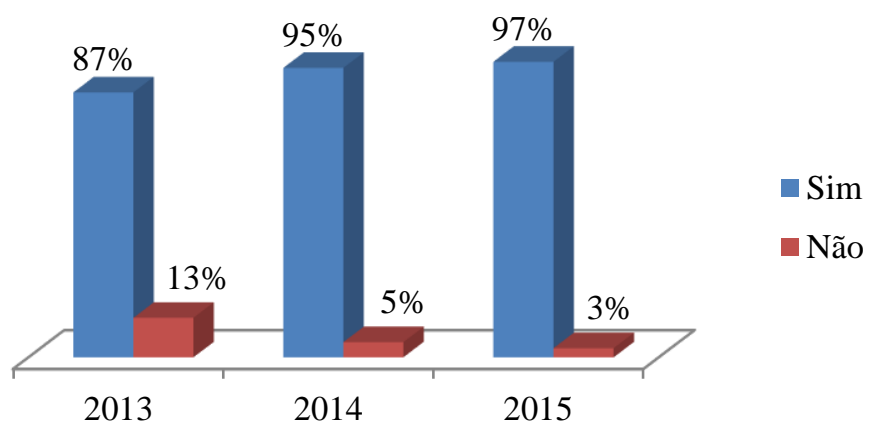

Gráfico 5. Interesse em participar de questões ambientais Fonte: Prefeitura da UFPA 2013,2014 e 2015 


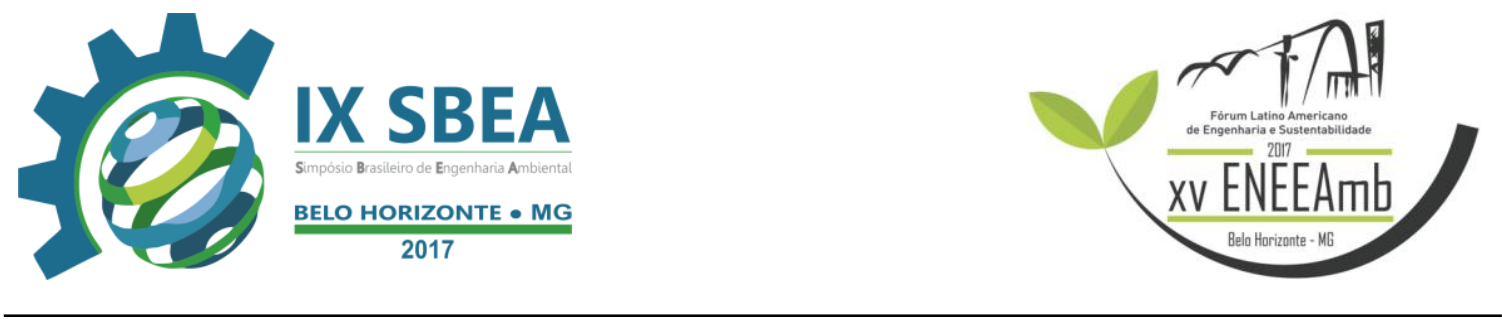

\section{Balanço de peso}

Ao longo da realização do Trote Solidário e Sustentável foi arrecado uma grande quantidade de papel que seria destinado de forma incorreta. Portanto a ação vem contribuir com a Política Nacional de Resíduos Sólidos (PNRS) que aponta o reconhecimento dos resíduos recicláveis como um bem econômico que possui valor social, isto é, um material que desperta a capacidade de valorização a partir do momento que os indivíduos realizam sua comercialização, garantindo um complemento e/ou, se não, a geração de renda (BRASIL, 2010). Por isso, o trote contribui com o lado social, visto que, os materiais foram destinados às cooperativas e associações ligadas a UFPA por meio do Programa Coleta Seletiva Solidária.

Tabela 1 - Quantidade de papel arrecado durante a ação

\begin{tabular}{ll}
\hline Período por mês/ano & Peso em Kg \\
\hline De 04 a 12 de abril de 2013 (7 dias) & 1.072 \\
De 24 a 28 de fevereiro de 2014 (5 dias) & 1.493 \\
De 03 a 06 de março de 2015 (4 dias) & 1.555 \\
Total & $\mathbf{4 . 0 5 1}$ \\
\hline \multicolumn{2}{c}{ Fonte: Prefeitura da UFPA 2013,2014 e 2015 }
\end{tabular}

Fonte: Prefeitura da UFPA 2013,2014 e 2015

\section{CONCLUSÕES}

As atividades do trote solidário e sustentável, "O Papel do Calouro da UFPA", realizados durante os três anos, serviram para relatar as experiências no processo de incentivo a EA na Cidade Universitária Prof. José da Silveira Netto da UFPA. Portanto, os questionários aplicados foram instrumentos para traçar um perfil dos alunos que estão adentrando a universidade.

Os resultados apontaram que os novos alunos da UFPA, participantes do trote, têm um perfil de maior consciência ambiental ao uso sustentável dos recursos naturais. Eles Estes responderam que o trote é um mecanismo importante, pois fortalece as práticas ambientais. Os calouros demonstram ter conhecimento sobre coleta seletiva. Isto pode indicar maior aceitação quanto aos para projetos ambientais. A motivação para que destinassem o material reciclável (papel) para o trote, foi o não desperdício do 


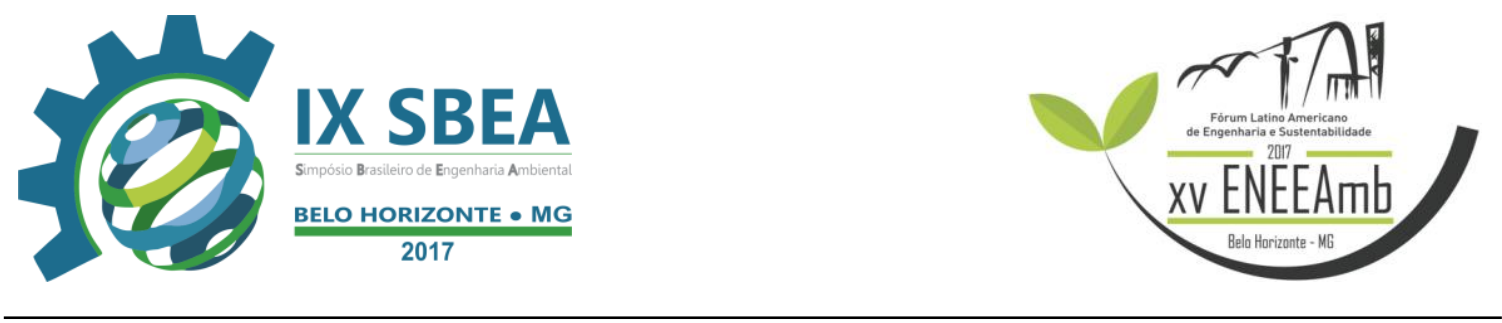

mesmo ou uma destinação adequada. Para a questão final, $90 \%$ dos entrevistados declarou interesse em participar de ações de cunho socioambiental.

As arrecadações durante os anos de 2013, 2014 e 2015 em kg atingiram as marcas respectivamente de 1.072, 1.493 e 1.555. Através dos resultados, pode-se concluir que as atividades de EA promovidas pela CMA têm motivado os alunos recémchegados assim como comunidade universitária como um todo a adoção de novos hábitos quanto a, separação e destinação dos materiais recicláveis, bem como ao exercício a responsabilidade socioambiental.

\section{REFERÊNCIAS BIBLIOGRÁFICAS}

BRASIL, MINISTÉRIO DO MEIO AMBIENTE. Lei $\mathbf{N}^{\mathbf{0}} \mathbf{9 . 7 9 5}$, de 27 de abril de 1999.

BRASIL. Presidência da República. Casa Civil. Lei no 12.305, de 2 de agosto de 2010. Institui a Política Nacional de Resíduos Sólidos; altera a Lei n ${ }^{\circ}$ 9.605, de 12 de fevereiro de 1998; e dá outras providências. Disponível em: <www.planalto.gov.br/ccivil_03/_ato2007-2010/2010/lei/112305.htm>. Acesso em: 19 Nov. 2015.

DÍAZ, Alberto Pardo. Educação ambiental como projeto. $2^{\text {a }}$ ed. Porto Alegre: Artmed, 2002.

JACOBI, Pedro. Educação e meio ambiente - transformando as práticas. Revista brasileira de educação ambiental. Brasília. v. 0. 2004. p.28-35

VARGAS, Liliana Angel. Educação Ambiental: a base para uma ação político/transformadora na Sociedade. Revista Eletrônica do Mestrado em Educação Ambiental. v. 15, jul./dez. 2005, p. 72-79. 